\title{
Blastocystis infection in Malaysia: Evidence of waterborne and human-to-human transmissions among the Proto-Malay, Negrito and Senoi tribes of Orang Asli
}

Tengku Shahrul Anuar ${ }^{1}$, Mohamed Kamel Abdul Ghani², Siti Nor Azreen ${ }^{1}$, Fatmah Md Salleh ${ }^{1}$ and Norhayati Moktar ${ }^{1 *}$

\begin{abstract}
Background: Blastocystis has been described as the most common intestinal parasite in humans and has an increased impact on public health. However, the transmission of this parasite has not been conclusively determined.

Methods: To contribute to a better comprehension of the epidemiology of this infection, a cross-sectional survey aimed at providing the first documented data on the prevalence and risk factors associated with Blastocystis infection was carried out among three Orang Asli tribes (Proto-Malay, Negrito and Senoi) in selected villages at Negeri Sembilan, Perak and Pahang, Peninsular Malaysia. Faecal samples were examined by formalin-ether sedimentation and trichrome staining techniques.

Results: Of 500 individuals, 20.4\% (102) were detected positive for Blastocystis; 13.3\% (20/150) of Proto-Malays, 21.6\% (30/139) of Negritos and 24.7\% (52/211) of Senois were positive for Blastocystis, respectively. The positive cases showed a decrease with increasing age and most of the positive cases were observed in individuals less than 15 years old. Multivariate analysis confirmed that drinking untreated water and the presence of other family members infected with Blastocystis were significant risk factors of infection among the three tribes and overall population studied.

Conclusion: Essentially, the findings highlighted that Blastocystis infection is prevalent among Orang Asli communities in Malaysia. Further studies using molecular approaches to distinguish the subtype of Blastocystis is needed. The present study also revealed that this infection may be transmitted through waterborne and humanto-human contact. Therefore, interventions with the provision of clean water supply for the communities and health education especially to the parents are urgently required.
\end{abstract}

Keywords: Blastocystis, Waterborne, Human-to-human, Orang Asli, Malaysia

\footnotetext{
*Correspondence: syahbasree@yahoo.com

'Department of Parasitology and Medical Entomology, Faculty of Medicine, Universiti Kebangsaan Malaysia, Jalan Raja Muda Abdul Aziz, 50300, Kuala Lumpur, Malaysia

Full list of author information is available at the end of the article
} 


\section{Background}

Blastocystis is an anaerobic unicellular eukaryote that can inhabit the intestinal track of humans and many animals, it was first described in 1912 [1]. Numerous cross-sectional surveys have been carried out in different epidemiological settings and hence Blastocystis is known to be one of the most frequently found protozoan parasites in human faecal samples, especially in children and adults in developing countries [2,3]. Blastocystis prevalence in human often exceeds $5 \%$ in industrialized countries and can reach as high as $76 \%$ in developing countries $[3,4]$. However, prevalence data are largely dependent on the methods used for detection. The most common diagnostic technique used worldwide for identification of Blastocystis is the permanent stain. The use of xenic cultures in which Blastocystis is grown in vitro with non-specific microorganisms have been shown to be more sensitive in detecting Blastocystis but it is not commonly used in the diagnostic laboratory [5-7]. Several forms of Blastocystis are observed in faecal samples include vacuolar, multivacuolar, avacuolar, granular, amoeboid and cyst [2]. However, most laboratories recognize only the vacuolar form as the diagnostic stage since it can be easily distinguished from other protozoa.

Although its role in human disease has been widely debated in the literature during the two last decades, numerous recent in vivo and in vitro studies strongly suggest that Blastocystis is a pathogen [8-10]. Case reports have linked Blastocystis infection with various gastrointestinal and extraintestinal symptoms including diarrhea, abdominal pain, depression, fatigue, vomiting, constipation, anorexia, urticaria, skin rash, headaches and flatulence, but this parasite may also play a significant role in several chronic gastrointestinal illnesses such as irritable bowel syndrome and inflammatory bowel disease [11-14]. An epidemiological study on Blastocystis showed that the animal handlers have a higher risk of infection and that there is always the possibility of transmission between animals and human [15]. On the other hand, polymerase chain reaction (PCR)-based methodology has demonstrated that there might exist a human-to-human infection among small communities, suggesting that transmission also occurs through the faecal-oral route like other common gastrointestinal parasites [16,17]. Furthermore, transmission can be facilitated by the contamination of the environment, food or water with excreted cysts from the reservoir hosts [18]. Thus, the mode of transmission of the Blastocystis has not been conclusively determined [17].

In Malaysia, Blastocystis infection has been reported to have a high prevalence among urban and rural communities and also in the water of rivers from recreational areas [19-21]. However, knowledge of the epidemiology and risk factors of Blastocystis infection is also rather limited.
Therefore, this study was carried out to determine the prevalence of Blastocystis and to investigate its association with the socioeconomic characteristics of three Orang Asli (Aborigine) tribes, namely Proto-Malay, Negrito and Senoi in Peninsular Malaysia.

\section{Methods}

\section{Study area and population surveyed}

A series of cross-sectional surveys were conducted in three different states of Peninsular Malaysia in Jelebu ( $2^{\circ} 55^{\prime} \mathrm{N}$ latitude, $102^{\circ} 4^{\prime}$ E longitude), Gerik ( $5^{\circ} 26^{\prime} \mathrm{N}$ latitude, $101^{\circ} 7^{\prime} \mathrm{E}$ longitude) and Temerloh ( $3^{\circ} 43^{\prime} \mathrm{N}$ latitude, $102^{\circ} 22^{\prime}$ E longitude) from June to December 2011 (Figure 1). Details of the studied villages and the populations sampled have been described elsewhere [22].

\section{Sample size}

By using the formula provided by Kish [23], the expected sample size was calculated according to the following parameters: expected prevalence of Blastocystis at $4.4 \%$ and $17 \%[24,25]$, confidence interval of $9.5 \%$ and absolute precision $(d)=0.05$ [26]. The required minimum sample size needed in this study was 65 individuals and the maximum would be 217 individuals in each tribe.

\section{Questionnaire}

A structured questionnaire was developed in English and then translated to Bahasa Melayu (the national language of Malaysia). The questionnaire was pre-tested among Orang Asli individuals who were admitted to Gombak Hospital, Selangor state. Trained research assistants interviewed participants in person, asking questions for demographic data (i.e., age, gender and education level), socioeconomic background (i.e., occupation, household income and educational status), behavioral risks (i.e., personal hygiene such as hand washing and food consumption), environmental sanitation and living condition characteristics (i.e., types of water supply, latrine system, sewage disposal system and presence of domestic animals). Participants were also asked if they had diarrhea and symptoms of gastroenteritis (i.e., vomiting, nausea, abdominal pain, watery stools and blood or mucus stools). For children, the questionnaire was completed by interviewing their parents or the guardian who had given informed consent.

Field and laboratory procedures: Detection of Blastocystis Following the administration of the questionnaire, a wide mouth screw-capped container pre-labelled with the individual's name and code was distributed to each participant for the collection of a faecal sample the next day. Their ability to recognize their name was counterchecked. The participant was instructed to scoop a thumb sized faecal sample using a provided scoop into the 


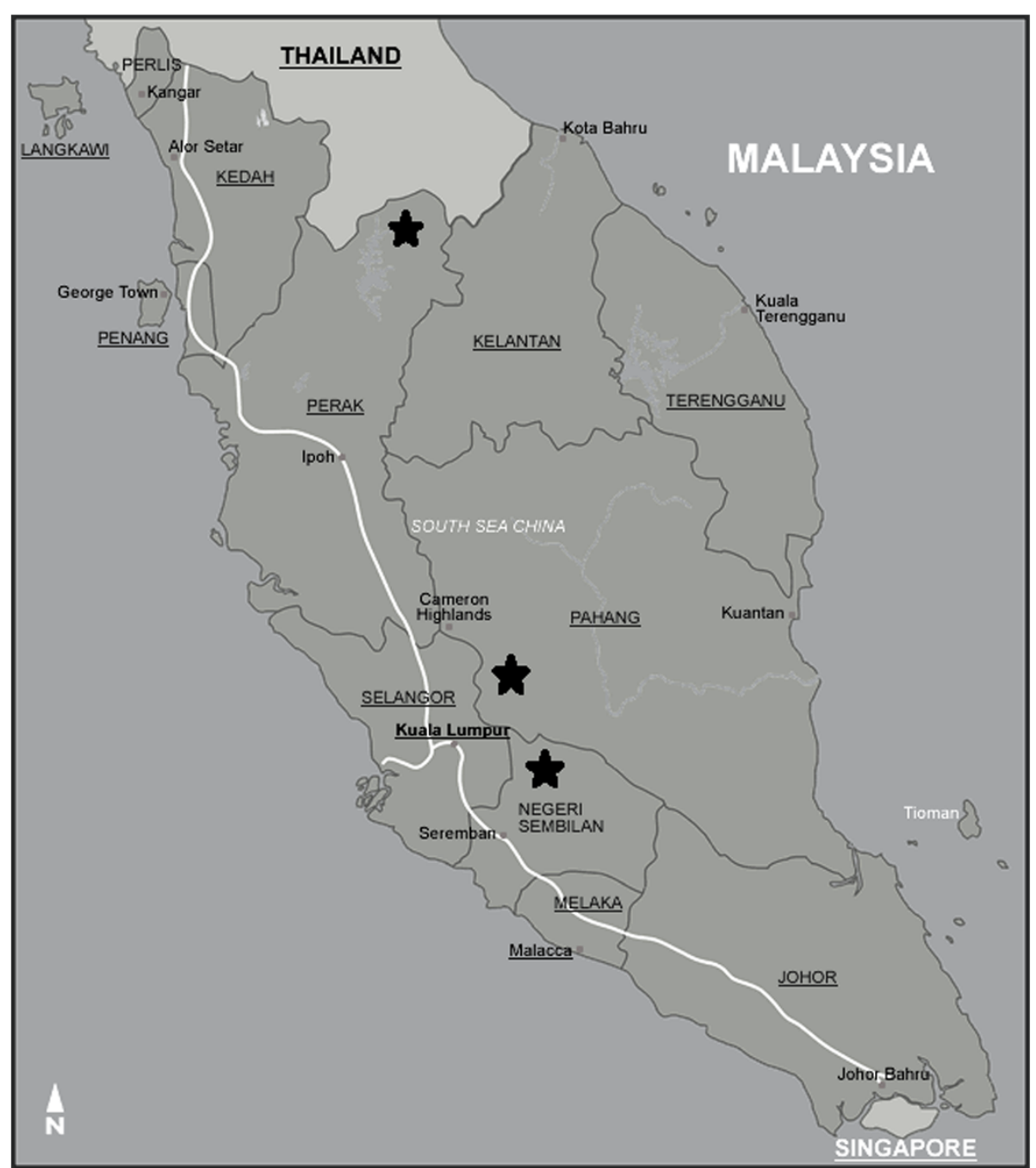

Figure 1 Map showing the location of the villages in Peninsular Malaysia involved in the study (stars).

container. Then, the container was placed in a zip-locked plastic bag. Parents and guardians were instructed to monitor their children during the sample collection in order to ensure that they placed their faecal samples into the correct container. All study participants were asked to provide a sufficiently large faecal sample (at least 10 grams) so that both formalin-ether sedimentation and trichrome staining techniques could be performed. This study had to rely on a single faecal sample collection because of the limitation of resources and the cultural belief of the aborigines against giving of their faecal samples.

Faecal samples were processed in the designated area of work in the study village within a maximum of six hours after collection by experienced laboratory technicians. Approximately 5 grams of each faecal sample were kept in a $15 \mathrm{ml}$ centrifuge tube containing $3 \mathrm{ml}$ polyvinyl alcohol (PVA). PVA-fixed samples were forwarded to the parasitological department of the
Faculty of Medicine, Universiti Kebangsaan Malaysia. The samples were subjected to trichrome staining. Briefly, the smear cover slip was stained as follows: iodine alcohol (15 minutes), 70\% alcohol (10 minutes), trichrome stain (10 minutes), acid alcohol (3 seconds), 95\% alcohol (5 minutes), absolute alcohol (5 minutes) and wintergreen oil (5 minutes) [27]. The cover slip was mounted using DPX and examined under a light microscope at magnifications of 1000x. Additionally, another half of the samples were kept unfixed and stored at $4{ }^{\circ} \mathrm{C}$ upon arrival at the laboratory for further analysis using formalin-ether sedimentation. Briefly, 2 grams of faecal sample were mixed with $7 \mathrm{ml}$ of formalin and $3 \mathrm{ml}$ of ether, centrifuged, stained with Lugol's iodine and finally examined under a light microscope at magnifications of 400x [28]. The sample was reported as positive if cysts and/or vacuolar forms of Blastocystis were detected by any of these two techniques (Figure 2). 


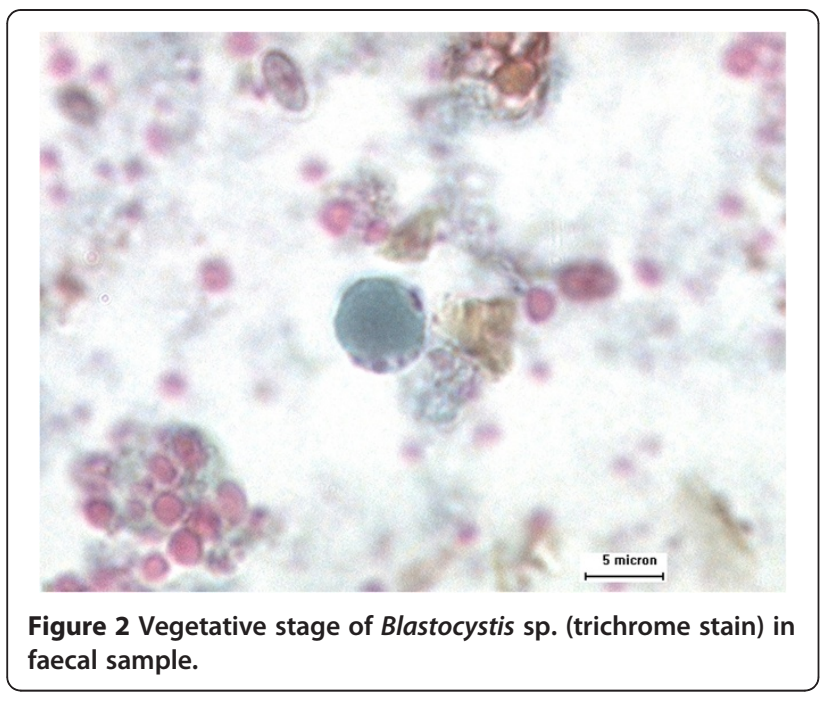

Data management and analysis

Data was entered into a Microsoft Access and was cross-checked by the technical staff in order to ensure that data were entered correctly. Statistical analysis was performed using the SPSS version 20 (SPSS, Chicago, IL, USA). Only those individuals who had formalin-ether sedimentation and trichrome staining results together with complete questionnaire data were included in the final analyses.

For descriptive analysis, rate (percentage) was used to describe the characteristics of the studied population, including the prevalence of Blastocystis. A Chi-squares test $\left(\chi^{2}\right)$ was used to test the associations between the variables. In the univariate analysis, the dependent variable was prevalence of Blastocystis, while the independent variables were demographic (gender and age group) and socioeconomic factors, behavioral risks, environmental sanitation, living condition characteristics and gastrointestinal symptoms. All variables that were significantly associated with the prevalence of Blastocystis in the univariate model were included in a logistic regression analysis to identify the risk factors for Blastocystis infection with control for the effects of possible confounders. For each statistically significant factor, an odds ratio (OR) and 95\% confidence interval (CI) were computed by the univariate and multivariate logistic regression analyses. The level of statistical significance was set as $p<0.05$. Furthermore, Mantel-Haenszel Chi-square test was used to test whether there is any confounding effect of the contingency tables.

\section{Ethical issues}

Prior to data collection, the study protocol (Reference Number: UKM 1.5.3.5/244/FF-165-2011) was reviewed and approved by the Ethics Committee of Universiti Kebangsaan Malaysia Medical Centre (UKMMC) and permission for field work was obtained from the Department of Orang Asli Development (JAKOA). Village meetings were held and village authorities and villagers were handed detailed explanations of the aims, procedures, potential risks and benefits of the study. During the meeting, they were also informed that their identity and personal information would be kept strictly confidential, and they could withdraw from the study at any point of time without citing reasons for doing so. If they agreed to participate, their consent was obtained in written form signature (or thumbprint for those who were illiterate) or parents were approached for consent on behalf of their children.

\section{Results}

Demographic and socioeconomic profiles

A total of 500 individuals aged from 2 to 74 years participated in this study with a median age of 18 years [interquartile range (IQR) 9-35]; and consisted of 150 (30\%) Proto-Malays, 139 (28\%) Negritos and 211 (42\%) Senois.

Overall, the studied population came from a low socioeconomic background with more than half having less than 6 years of formal education. A high percentage of household income of less than RM500.00 (US\$ 162.42) was predominantly seen in the Negrito $(82.7 \%)$ and Senoi (60.7\%) tribes. Most (95.3\%) houses in ProtoMalay villages had piped water supplies and toilet facilities; conversely piped water supplies and safe sewage disposal facilities were lacking in the villages of the Negrito and Senoi tribes. General characteristics of each tribe, including their demographic and socioeconomic profiles are presented in Table 1.

\section{Prevalence and distribution of Blastocystis infection}

The prevalence and distribution of Blastocystis infection are shown in Table 2. The overall prevalence of this infection was $20.4 \%$. It is evident that, of 139 individuals studied from the Negrito tribe, $21.6 \%$ were infected with Blastocystis. However, individuals from the Senoi tribe had a relatively high prevalence of this infection which was $24.7 \%$, whereby only $13.3 \%$ of the Proto-Malays reported positive for Blastocystis. Overall, the positive cases decreased with increasing age and most of the positive cases were observed in individuals of less than 15 years old. Similar findings were observed in the Proto-Malay, Negrito and Senoi tribes. The overall prevalence of Blastocystis was higher in females, with similar observations seen in all tribes. However, there was no significant difference of this infection between genders. With regards to tribe, it was observed that the Senoi presented a greater risk of Blastocystis infection than the Negrito and Proto-Malay tribes. On the other 
Table 1 General characteristics of the Orang Asli communities that participated in this study

\begin{tabular}{|c|c|c|c|c|}
\hline Characteristics/Tribes & Overall & Proto-Malay & Negrito & Senoi \\
\hline & n (\%) & n (\%) & n (\%) & n (\%) \\
\hline \multicolumn{5}{|l|}{ Age groups (years) } \\
\hline$<15$ & $221(44.2)$ & $59(39.3)$ & $72(51.8)$ & $90(42.7)$ \\
\hline$\geq 15$ & $279(55.8)$ & $91(60.7)$ & $67(48.2)$ & $121(57.3)$ \\
\hline \multicolumn{5}{|l|}{ Gender } \\
\hline Male & $219(43.8)$ & $66(44.0)$ & $66(47.5)$ & $87(41.2)$ \\
\hline Female & $281(56.2)$ & $84(56.0)$ & $73(52.5)$ & $124(58.8)$ \\
\hline \multicolumn{5}{|l|}{ Socioeconomic status } \\
\hline Father's education ( $<6$ years) & $222(74.0)$ & $54(66.7)$ & $68(77.3)$ & $100(76.3)$ \\
\hline Mother's education ( $<6$ years) & $232(56.2)$ & $53(65.4)$ & $77(87.5)$ & $102(77.9)$ \\
\hline Low monthly household income (<RM500) & $260(52.0)$ & $17(11.3)$ & $115(82.7)$ & $128(60.7)$ \\
\hline Working mothers & $153(51.0)$ & $45(55.6)$ & $33(37.5)$ & $75(57.3)$ \\
\hline Large family ( $\geq 8$ members) & $171(34.2)$ & $32(21.3)$ & $63(45.3)$ & $76(36.0)$ \\
\hline Supplied with piped water & $357(71.4)$ & $143(95.3)$ & $76(54.7)$ & $138(65.4)$ \\
\hline Presence of toilet at household) & $308(61.6)$ & $143(95.3)$ & $48(34.5)$ & $117(55.5)$ \\
\hline
\end{tabular}

RM = Malaysian Ringgit; (US\$100 $=$ RM307.85) [ $1^{\text {st }}$ February 2013].

$\mathrm{n}=$ Number examined

hand, there was no significant difference in the prevalence of Blastocystis infection among these three tribes.

\section{Co-infection with other intestinal parasites}

For all positive faecal samples with Blastocystis $(\mathrm{n}=102)$, $82.4 \%$ showed co-infection with one or more other parasites. Trichuris trichiura (53.9\%) was the most common intestinal parasite found in conjunction with Blastocystis, followed by Ascaris lumbricoides (29.4\%), Entamoeba histolytica/dispar/moshkovskii (26.5\%), Entamoeba hartmanni (22.6\%), Entamoeba coli (20.6\%), Giardia intestinalis (17.7\%), Iodamoeba butschlii (13.7\%), Endolimax nana (6.9\%), hookworm (5.9\%) and Chilomastix mesnilii (2\%). Furthermore, twelve samples were isolated from symptomatic subjects.

\section{Risk factors for Blastocystis infection}

Univariate analysis identified drinking untreated water $(\mathrm{OR}=2.92 ; 95 \% \mathrm{CI}=1.84,4.63 ; p<0.001)$, not washing hands after playing with soil or gardening $(\mathrm{OR}=1.58$; 95\% CI $=1.02,2.45 ; p=0.040)$ and the presence of other family members infected with Blastocystis ( $\mathrm{OR}=8.21$; $95 \% \mathrm{CI}=5.07,13.30 ; p<0.001)$ as the main risk factors for the overall population studied (Table 3). In ProtoMalays, drinking untreated water $(\mathrm{OR}=6.25$; $95 \%$ $\mathrm{CI}=1.52,25.70 ; p=0.019)$ and the presence of other family members infected with Blastocystis ( $\mathrm{OR}=21.48$; 95\% $\mathrm{CI}=6.70,68.82 ; p<0.001)$ were identified as risk factors for Blastocystis (Table 4). In Negritos, drinking untreated water $(\mathrm{OR}=2.79 ; 95 \% \mathrm{CI}=1.10,7.03$; $p=0.026)$ and the presence of other family members infected with Blastocystis $(\mathrm{OR}=6.19 ; 95 \% \mathrm{CI}=2.55$,

Table 2 Prevalence of Blastocystis infection among different Orang Asli tribes according to age groups and gender

\begin{tabular}{|c|c|c|c|c|c|c|c|c|c|c|c|c|}
\hline & \multicolumn{3}{|c|}{ Overall } & \multicolumn{3}{|c|}{ Proto-Malay } & \multicolumn{3}{|c|}{ Negrito } & \multicolumn{3}{|c|}{ Senoi } \\
\hline & $n$ & $n$ & $\%$ & $n$ & $n$ & $\%$ & $n$ & $n$ & $\%$ & $n$ & $n$ & $\%$ \\
\hline & positive & tested & positive & positive & tested & positive & positive & tested & positive & positive & tested & positive \\
\hline \multicolumn{13}{|c|}{ Age groups (years) } \\
\hline$<15$ & 50 & 221 & 22.6 & 10 & 59 & 17.0 & 16 & 72 & 22.2 & 24 & 89 & 27.0 \\
\hline$\geq 15$ & 52 & 279 & 18.6 & 10 & 91 & 11.0 & 14 & 67 & 20.9 & 28 & 122 & 23.0 \\
\hline \multicolumn{13}{|l|}{ Gender } \\
\hline Male & 41 & 219 & 18.7 & 8 & 66 & 12.1 & 14 & 66 & 21.2 & 19 & 87 & 21.8 \\
\hline Female & 61 & 281 & 21.7 & 12 & 84 & 14.3 & 16 & 73 & 21.9 & 33 & 124 & 26.6 \\
\hline Total & 102 & 500 & 20.4 & 20 & 150 & 13.3 & 30 & 139 & 21.6 & 52 & 211 & 24.7 \\
\hline
\end{tabular}

$\mathrm{n}=$ Number examined. 
Table 3 Potential risk factors associated with Blastocystis infection among the overall population studied (univariate analysis, $\mathbf{n}=\mathbf{5 0 0}$ )

\begin{tabular}{llcccr}
\hline Variables & & No. examined & Infected (\%) & OR (95\% Cl) & \multicolumn{1}{c}{-value } \\
\hline Age (years) & & & & & \\
& $<15$ & 221 & 22.6 & $1.28(0.83,1.97)$ & 0.272 \\
& $\geq 15$ & 279 & 18.6 & 1
\end{tabular}

Gender

$\begin{array}{ll}\text { Female } & 281 \\ \text { Male } & 219\end{array}$

Drinking untreated water

Bathing and washing in the river

$\begin{array}{ll}\text { Yes } & 143 \\ \text { No } & 357\end{array}$

Not washing hands after playing with soil or gardening

$\begin{array}{ll}\text { Yes } & 197 \\ \text { No } & 303\end{array}$

Presence of domestic animals

Yes $\quad 309$

Indiscriminate defecation

Sewage disposal

$$
\text { Outdoor }
$$

Eating with hands

$\begin{array}{ll}\text { Yes } & 328 \\ \text { No } & 172\end{array}$

Consuming raw vegetables

\section{Yes}

No

Eating fresh fruits

$$
\text { Yes }
$$$$
\text { No }
$$

Father's education

$$
\begin{gathered}
\text { Non-educated (<6 yrs) } \\
\text { Educated ( }>6 \text { yrs) }
\end{gathered}
$$

Mother's education

$$
\begin{gathered}
\text { Non-educated (<6 yrs) } \\
\text { Educated ( }>6 \text { yrs) }
\end{gathered}
$$

Working mothers

$$
\text { Yes }
$$$$
\text { No }
$$ 
Table 3 Potential risk factors associated with Blastocystis infection among the overall population studied (univariate analysis, $\mathbf{n}=\mathbf{5 0 0}$ ) (Continued)

\begin{tabular}{|c|c|c|c|c|}
\hline \multicolumn{5}{|l|}{ Household members } \\
\hline$\geq 8$ & 171 & 21.6 & $1.12(0.71,1.77)$ & 0.621 \\
\hline$<8$ & 329 & 19.8 & 1 & \\
\hline \multicolumn{5}{|l|}{ Household monthly income } \\
\hline$<\operatorname{RM} 500$ & 260 & 23.5 & $1.49(0.96,2.32)$ & 0.077 \\
\hline$>\mathrm{RM} 500$ & 240 & 17.1 & 1 & \\
\hline \multicolumn{5}{|c|}{ Other family members infected with Blastocystis } \\
\hline Yes & 116 & 50.9 & $8.21(5.07,13.30)$ & $<0.001^{a, b}$ \\
\hline No & 384 & 11.2 & 1 & \\
\hline
\end{tabular}

RM = Malaysian Ringgit; (US\$100 = RM307.85) [ $1^{\text {st }}$ February 2013].

Reference group marked as OR $=1$ [OR = Odds Ratio].

$\mathrm{Cl}=$ Confidence interval.

a Significant association $(p<0.05)$.

b Variables were confirmed by multivariate analysis as significant risk factors.

14.98; $p<0.001)$ were the predictors for Blastocystis infection (Table 4). Three risk factors were found to be positively significant in Senois; drinking untreated water $(\mathrm{OR}=2.35 ; 95 \% \mathrm{CI}=1.10,5.03 ; p=0.025)$, not washing hands after playing with soil or gardening $(\mathrm{OR}=2.00$; $95 \% \mathrm{CI}=1.06,3.78 ; p=0.031$ ) and the presence of other family members infected with Blastocystis $(\mathrm{OR}=6.11$; 95\% CI $=3.10,12.03 ; p<0.001$ ) (Table 4).

Logistic regression analysis of the overall population studied again confirmed that drinking untreated water $(\mathrm{OR}=2.75 ; 95 \% \mathrm{CI}=1.66,4.55 ; p<0.001)$ and the presence of other family members infected with Blastocystis $(\mathrm{OR}=7.96$; $95 \% \mathrm{CI}=4.84,13.08 ; p<0.001)$ as the real risk factors for Blastocystis infection. Similar observations were also identified in the Proto-Malay, Negrito and Senoi tribes.

\section{Discussion}

The epidemiological studies on Blastocystis infection have been inconclusive in several aspects, particularly regarding the source of infection and mode of transmission [29,30]. Several studies have indicated human-to -human and animal-to-animal transmission models and it has been revealed that the cyst form was the only transmissible stage of this parasite [31,32]. A recent study by Lee et al. [33] provided molecular evidence supporting zoonotic transmission of Blastocystis in a rural community in Nepal. On the other hand, the prevalence of Blastocystis infection might be varied due to the laboratory method used for detection, age group and hygienic condition of the population studied [34]. However, high prevalence reported from developing countries confirmed that poor hygiene was involved in the transmission of the disease.

In the present study, the overall prevalence of Blastocystis among Orang Asli in Malaysia was 20.4\%, which differs from previous local reports $[19,24,35,36]$ but in agreement with the latest report by Abdulsalam et al. [21]. Comparing our findings with studies from other countries showed that the prevalence reported by the present study was similar to those reported in Jordan (25\%), Brazil (26.5\%), Colombia (22.4\%) and Nepal (26.1\%) [37-40]. However, the prevalence rate of the infections observed in this study is higher than reported in Thailand and India $[34,41]$. In contrast, considerably higher prevalence rates of $31 \%, 48.7 \%$, 32\% and $40.7 \%$ were reported among Egyptians, Filipinos, Pakistanian and Argentinean individuals, respectively [12,42-44]. Our findings showed no significant difference in the prevalence of Blastocystis infection according to age and gender of the participants, and this is consistent with the results of previous reports $[18,19,21,40]$. However, a study carried out by Li et al. [45] demonstrated that individuals aged 60 years and above had the highest prevalence of Blastocystis in Shanghai municipality and Yangjia country, which is similar to a finding reported from Glasgow [7]. Furthermore, Al-Fellani et al. [46] reported males were more frequently infected (28.98\%) with Blastocystis than females (23.89\%) and the difference was statistically significant. Likewise, several studies also reported significantly higher prevalence in male than female subjects $[37,47]$.

This present study demonstrated that the prevalence rates of this infection were higher in Negritos and Senois than the Proto-Malay tribe. This could be attributed to the lack of basic amenities in the Negrito and Senoi tribes where almost $50 \%$ of the communities are not accessed to piped water supply and safe toilet facilities. It indicates that the poor provision of basic amenities plays an important role in the transmission of Blastocystis in Senois and Negritos. Similar findings were seen in Entamoeba histolytica/dispar/moshkovskii infection carried out in the same communities which 
Table 4 Associations between Blastocystis infection and risk factors among different Orang Asli tribes

\begin{tabular}{|c|c|c|c|c|c|c|c|c|c|c|c|c|}
\hline \multirow{3}{*}{ Variables } & \multicolumn{4}{|c|}{ Proto-Malay $(n=150)$} & \multicolumn{4}{|c|}{ Negrito $(n=139)$} & \multicolumn{4}{|c|}{ Senoi $(n=211)$} \\
\hline & \multirow{2}{*}{$\begin{array}{c}\text { No. } \\
\text { examined }\end{array}$} & \multirow{2}{*}{$\begin{array}{c}\text { Infected } \\
(\%)\end{array}$} & \multirow{2}{*}{$\begin{array}{c}\text { OR } \\
(95 \% \mathrm{Cl})\end{array}$} & \multirow[t]{2}{*}{$\overline{p \text {-value }}$} & \multirow{2}{*}{$\begin{array}{c}\text { No. } \\
\text { examined }\end{array}$} & \multirow{2}{*}{$\begin{array}{l}\text { Infected } \\
(\%)\end{array}$} & \multirow{2}{*}{$\begin{array}{c}\text { OR } \\
(95 \% \mathrm{Cl})\end{array}$} & \multirow[t]{2}{*}{$p$-value } & \multirow{2}{*}{$\begin{array}{c}\text { No. } \\
\text { examined }\end{array}$} & \multirow{2}{*}{$\begin{array}{c}\text { Infected } \\
(\%)\end{array}$} & \multirow{2}{*}{$\begin{array}{c}\text { OR } \\
(95 \% \mathrm{Cl})\end{array}$} & \multirow[t]{2}{*}{$p$-value } \\
\hline & & & & & & & & & & & & \\
\hline \multicolumn{13}{|l|}{ Age (years) } \\
\hline$<15$ & 59 & 16.9 & $1.65(0.64,4.26)$ & 0.294 & 72 & 22.2 & $1.08(0.48,2.43)$ & 0.849 & 90 & 26.7 & $1.21(0.64,2.67)$ & 0.557 \\
\hline$\geq 15$ & 91 & 11.0 & 1 & & 67 & 20.9 & 1 & & 121 & 23.1 & 1 & \\
\hline \multicolumn{13}{|l|}{ Gender } \\
\hline Female & 84 & 14.3 & $1.21(0.46,3.15)$ & 0.699 & 73 & 21.9 & $1.04(0.46,2.34)$ & 0.920 & 124 & 26.6 & $1.30(0.68,2.48)$ & 0.428 \\
\hline Male & 66 & 12.1 & 1 & & 66 & 21.2 & 1 & & 87 & 21.8 & 1 & \\
\hline \multicolumn{13}{|l|}{ Drinking untreated water } \\
\hline Yes & 9 & 44.4 & $6.25(1.52,25.70)$ & $0.019^{a, b}$ & 79 & 28.0 & $2.79(1.10,7.03)$ & $0.026^{a, b}$ & 144 & 29.2 & $2.35(1.10,5.03)$ & $0.025^{\mathrm{a}, \mathrm{b}}$ \\
\hline No & 141 & 11.3 & 1 & & 60 & 12.3 & 1 & & 67 & 14.9 & 1 & \\
\hline \multicolumn{13}{|c|}{ Bathing and washing in the river } \\
\hline Yes & 7 & 14.3 & $1.09(0.12,9.54)$ & 0.939 & 63 & 28.6 & $2.13(0.94,4.86)$ & 0.068 & 73 & 20.5 & $0.71(0.36,1.40)$ & 0.315 \\
\hline No & 143 & 13.3 & 1 & & 76 & 15.8 & 1 & & 138 & 26.8 & 1 & \\
\hline \multicolumn{13}{|c|}{ Not washing hands after playing with soil or gardening } \\
\hline Yes & 27 & 11.5 & $0.82(0.22,3.04)$ & 0.767 & 91 & 22.0 & $1.07(0.46,2.52)$ & 0.876 & 79 & 32.9 & $2.00(1.06,3.78)$ & $0.031^{\mathrm{a}}$ \\
\hline No & 123 & 13.7 & 1 & & 48 & 20.8 & 1 & & 132 & 19.7 & 1 & \\
\hline \multicolumn{13}{|c|}{ Presence of domestic animals } \\
\hline Yes & 120 & 14.2 & $1.49(0.41,5.44)$ & 0.548 & 70 & 16.7 & $0.61(0.26,1.45)$ & 0.261 & 119 & 27.7 & $1.45(0.77,2.81)$ & 0.237 \\
\hline No & 30 & 10.0 & 1 & & 69 & 24.7 & 1 & & 92 & 20.7 & 1 & \\
\hline \multicolumn{13}{|l|}{ Indiscriminate defecation } \\
\hline Yes & 7 & 14.3 & $1.09(0.12,9.54)$ & 0.939 & 91 & 23.1 & $1.30(0.54,3.11)$ & 0.555 & 94 & 23.4 & $0.89(0.47,1.67)$ & 0.708 \\
\hline No & 143 & 13.3 & 1 & & 48 & 18.8 & 1 & & 117 & 25.6 & 1 & \\
\hline \multicolumn{13}{|l|}{ Sewage disposal } \\
\hline Outdoor & 21 & 9.5 & $0.65(0.14,3.03)$ & 0.580 & 106 & 21.7 & $1.03(0.40,2.67)$ & 0.953 & 113 & 24.8 & $1.02(0.54,1.90)$ & 0.961 \\
\hline Common drainage & 129 & 14.0 & 1 & & 33 & 21.2 & 1 & & 98 & 24.5 & 1 & \\
\hline \multicolumn{13}{|l|}{ Eating with hands } \\
\hline Yes & 70 & 12.0 & $0.79(0.31,2.04)$ & 0.631 & 105 & 22.4 & $1.25(0.46,3.40)$ & 0.657 & 153 & 22.6 & $0.67(0.34,1.32)$ & 0.247 \\
\hline No & 80 & 14.7 & 1 & & 34 & 18.8 & 1 & & 58 & 30.4 & 1 & \\
\hline \multicolumn{13}{|l|}{ Consuming raw vegetables } \\
\hline Yes & 63 & 12.7 & $0.91(0.35,2.37)$ & 0.846 & 113 & 24.6 & $3.74(0.83,16.89)$ & 0.068 & 62 & 23.1 & $0.88(0.46,1.76)$ & 0.724 \\
\hline No & 87 & 13.8 & 1 & & 26 & 8.0 & 1 & & 149 & 25.3 & 1 & \\
\hline
\end{tabular}


Table 4 Associations between Blastocystis infection and risk factors among different Orang Asli tribes (Continued)

\begin{tabular}{|c|c|c|c|c|c|c|c|c|c|c|c|c|}
\hline \multicolumn{13}{|l|}{ Eating fresh fruits } \\
\hline Yes & 129 & 14.7 & $3.46(0.44,27.28)$ & 0.213 & 122 & 19.7 & $0.45(0.15,1.34)$ & 0.142 & 144 & 21.0 & $0.62(0.33,1.17)$ & 0.139 \\
\hline No & 21 & 4.8 & 1 & & 17 & 35.3 & 1 & & 67 & 29.9 & 1 & \\
\hline \multicolumn{13}{|l|}{ Father's education } \\
\hline Non-educated ( $<6$ yrs) & 54 & 14.8 & $1.00(0.27,3.67)$ & 1.000 & 68 & 26.5 & $2.04(0.53,7.79)$ & 0.290 & 100 & 28.0 & $1.33(0.52,3.44)$ & 0.551 \\
\hline Educated (>6 yrs) & 27 & 14.8 & 1 & & 20 & 15.0 & 1 & & 31 & 22.6 & 1 & \\
\hline \multicolumn{13}{|l|}{ Mother's education } \\
\hline Non-educated ( $<6$ yrs) & 53 & 18.9 & $3.02(0.61,14.89)$ & 0.158 & 77 & 22.1 & $0.50(0.13,1.90)$ & 0.298 & 102 & 30.4 & $2.73(0.88,8.50)$ & 0.075 \\
\hline Educated (>6 yrs) & 28 & 7.1 & 1 & & 11 & 36.4 & 1 & & 29 & 13.8 & 1 & \\
\hline \multicolumn{13}{|l|}{ Working mothers } \\
\hline Yes & 45 & 15.6 & $1.14(0.33,3.95)$ & 0.834 & 33 & 25.8 & $1.18(0.43,3.25)$ & 0.753 & 75 & 28.0 & $1.17(0.53,2.56)$ & 0.701 \\
\hline No & 36 & 13.9 & 1 & & 55 & 22.8 & 1 & & 56 & 25.0 & 1 & \\
\hline \multicolumn{13}{|l|}{ Household members } \\
\hline$\geq 8$ & 32 & 12.5 & $0.91(0.28,2.94)$ & 0.876 & 63 & 25.4 & $1.51(0.67,3.39)$ & 0.320 & 76 & 22.4 & $0.82(0.42,1.60)$ & 0.565 \\
\hline$<8$ & 118 & 13.6 & 1 & & 76 & 18.4 & 1 & & 135 & 25.9 & 1 & \\
\hline \multicolumn{13}{|l|}{ Household monthly income } \\
\hline$<$ RM500 & 17 & 17.6 & $1.46(0.38,5.62)$ & 0.578 & 115 & 24.3 & $3.54(0.78,16.01)$ & 0.083 & 128 & 23.4 & $0.85(0.45,1.60)$ & 0.613 \\
\hline$>$ RM500 & 133 & 12.8 & 1 & & 24 & 8.3 & 1 & & 83 & 26.5 & 1 & \\
\hline \multicolumn{13}{|c|}{ Other family members infected with Blastocystis } \\
\hline Yes & 18 & 61.1 & $21.48(6.70,68.82)$ & $<0.001^{\mathrm{a}, \mathrm{b}}$ & 33 & 48.5 & $6.19(2.55,14.98)$ & $<0.001^{a, b}$ & 65 & 49.2 & $6.11(3.10,12.03)$ & $<0.001^{a, b}$ \\
\hline No & 132 & 6.8 & 1 & & 106 & 13.2 & 1 & & 146 & 13.7 & 1 & \\
\hline
\end{tabular}

RM = Malaysian Ringgit: (US\$100 = RM307.85) [15t February 2013].

Reference group marked as $\mathrm{OR}=1$ [OR=Odds Ratio].

$\mathrm{Cl}=$ Confidence interval.

${ }^{\text {a }}$ Significant association $(p<0.05)$

${ }^{\mathrm{b}}$ Variables were confirmed by multivariate analysis as significant risk factors. 
reported a high prevalence rate of this infection among members of the Negritos who have poor housing conditions and basic amenities [48]. However, this finding contradicted previously reported prevalence of Giardia intestinalis infection carried out in the same communities which demonstrated a high prevalence rate of giardiasis among members of the Proto-Malay tribe who have a better housing condition and basic amenities [22]. Other family members infected with giardiasis were identified as a risk factor of the infection and human-to -human transmission was postulated as a main mode of transmission of giardiasis in the communities [22].

Waterborne transmission has been speculated as the mode of transmission of Blastocystis in several studies, especially those conducted in tropical countries and in travelers who just returned from these countries [37,49]. These travelers also gave a history of drinking untreated water while they were abroad [49]. On further analysis of risk factors using multivariate analysis, we found that those who drink untreated water or unboiled water were statistically significant for the Proto-Malay $(p=0.019)$, Negrito $(p=0.026)$ and Senoi tribes $(p=0.025)$. Moreover, drinking untreated water was also found to be a significant predictor of acquiring Blastocystis infection in the overall population studied $(p<0.001)$. It is interesting to note that although the prevalence rate of Blastocystis was low in Proto-Malays as compared to Senois and Negritos, and almost $95 \%$ of the population in Proto-Malay villages have access to piped water supply, individuals from the ProtoMalay tribe who drink untreated water or unboiled water have a higher risk of acquiring this infection as compared to individuals in Senoi and Negrito tribes. During the visits to the villages, we observed that most of the ProtoMalays preferred to drink unboiled water because it was tastier than boiled water. The cysts of Blastocystis are rather small compared to the cysts of other common protozoa such as Giardia intestinalis and Entamoeba histolytica [29]. Thus, it is likely that the cysts of Blastocystis could escape the conventional water filtration techniques [29]. Furthermore, cysts of Blastocystis were resistant to chlorine at the standard concentration used in tap water [50] and able to survive in water for up to 19 days at a normal temperature, but are fragile at extremes of heat and cold, and in common disinfectants [51,52]. All these characteristics made untreated water a suitable source of infection of this protozoa. Besides that, posttreatment contamination of drinking water that is usually stored in a bucket for household use and the common practice of drinking unboiled water might be the possible reason for the high risk. The unboiled or unfiltered drinking water might have been contaminated with Blastocystis cysts from faecal shedding, which may lead to Blastocystis infection as suggested by a group in Thailand and Nepal $[18,40]$. During the visit to the villages, we observed that $28.6 \%$ of the households from the three tribes used water from the wells, streams and rain with or without further treatment by filtration or boiling. Therefore, the present study provides baseline data for the role of waterborne transmission in Blastocystis infection among the Proto-Malay, Negrito and Senoi tribes. However, there is a need for further investigations to assess whether the reported association of Blastocystis infection and drinking untreated water is a causal association.

It is interesting to note that in the present study, the presence of other family members infected with Blastocystis has been identified as the significant risk factors $(p<0.001)$ among Proto-Malays, Negritos, Senois and overall population, respectively. This evidence suggests infection can occur within families and humanto-human transmission of Blastocystis is another possible mode of transmission identified in the present study. Sharing of poorly maintained sanitary facilities with a household may facilitate human-to-human transmission [40]. Therefore, maintaining clean sanitary facilities and practices are important to avoid transmission of Blastocystis to others. Furthermore, screening of other family members should also be recommended as one of the strategies in controlling Blastocystis infection in all tribes of Orang Asli communities as an infected family member appears to be an important risk factor for this infection. A family outbreak of Blastocystis infection with gastroenteritis has been reported [53]. Thus, the possibility of a Blastocystis outbreak is of concern. Likewise, a study done by Pipatsatitpong et al. [54] demonstrated that orphans who lived in the same room as childcare workers who were infected with Blastocystis had a higher risk of acquiring blastocystosis than those who lived in the rooms without infected childcare workers. Transmission of Blastocystis has also been reported among family members [55,56] and among mentally deficient persons in institutions $[57,58]$.

In the present study, we have been using both concentration technique and trichrome staining. Some authors suggested that concentration techniques were unsuitable to detect Blastocystis from faecal samples because the parasite could be easily disrupted [59]. In contrast, several other studies have reported that concentration techniques are useful $[60,61]$. Our results showed that trichrome stain was suitable for the diagnosis of Blastocystis infection. It is noted that all other reports on the prevalence of Blastocystis in Malaysia used different method which was in vitro cultivation. However, cultivation of the organism plays a minor role especially as results are available only after 48 to 72 hours [62]. This may not make them appropriate for comparison with this study. Nonetheless, these results could serve as baseline information on the prevalence and risk factors of Blastocystis among Orang Asli in Malaysia. 
The present study has several limitations. Firstly, the findings were based on formalin-ether sedimentation and trichrome staining techniques. We were unable to culture in Jones' medium due to limited faecal samples. By virtue of this fact, if in vitro cultivation was employed as a diagnostic tool, the prevalence of Blastocystis may be higher than the current reported prevalence due to its sensitivity. Secondly, the inconsistency between observation and response given by the subjects. These inconsistencies could be caused by differences in educational background among the Orang Asli.

\section{Conclusion}

In conclusion, this is the first study to comprehensively provide the prevalence and risk factors of Blastocystis infection among the Proto-Malay, Negrito and Senoi tribes. Our postulation concurs with the study carried out previously which reported that the transmission to humans was through drinking untreated water. Furthermore, the present study also observes human-to-human transmission appears to be one of the modes of transmission of Blastocystis in these communities. Therefore, it is suggested that an intervention strategy should be taken to protect the community and to advise them to drink boiled water. Screening and giving treatment to the infected family members on the basis of one affected member would appear to be justified in order to avoid or reduce the Blastocystis infection among Orang Asli.

\section{Competing interests}

The authors' declare that they have no competing interests.

\section{Authors' contributions}

TSA was involved in all phases of the study, including study design, data collection, data analysis and write up of the manuscript; NM and MKAG supervised the study, and revised the manuscript; NM and MKAG were involved in the statistical analysis of data; SNA and FMS were involved in the collection and laboratory examination of samples. All authors read and approved the final manuscript. TSA and NM are the guarantors of the paper.

\section{Financial support}

This work was supported in part by the UKMMC Fundamental Research Grant (FF-165-2011) and Special Research University Grant (UKM-GUP-2011316) from Universiti Kebangsaan Malaysia.

\section{Acknowledgements}

We gratefully acknowledge the Ministry of Rural and Regional Development Malaysia for granting us permission to conduct this research. We also thank all the participants from the Parit Gong village, Pasu village, Pian village, Bagan Balak village, Sungai Banun village, Desa Damai village, Sungai Raba village, and Pengkalan Permai village for their commitment and contribution in providing their faecal samples.

\section{Author details}

${ }^{1}$ Department of Parasitology and Medical Entomology, Faculty of Medicine, Universiti Kebangsaan Malaysia, Jalan Raja Muda Abdul Aziz, 50300, Kuala Lumpur, Malaysia. ${ }^{2}$ Programme of Biomedical Sciences, School of Diagnostic and Applied Health Sciences, Universiti Kebangsaan Malaysia, Jalan Raja Muda Abdul Aziz, 50300, Kuala Lumpur, Malaysia.

Received: 4 January 2013 Accepted: 15 February 2013

Published: 22 February 2013

\section{References}

1. Brumpt E: Colite a Tetramitus mesnili (Wenyon 1910) et colite a Trichomonas intestinalis Leuchart 1879. Blastocystis hominis n. sp. et forms voisines. Bull Soc Pathol Exot 1912, 5:725-730.

2. Stenzel DJ, Boreham PFL: Blastocystis hominis revisited. Clin Microbiol Rev 1996, 9:563-584

3. Tan KSW: New insights on classification, identification and clinical relevance of Blastocystis spp. Clin Microbiol Rev 2008, 21:639-665.

4. Dogruman-Al F, Simsek Z, Boorom K, Ekici E, Sahin M, Tuncer C, Kustimur S, Altinbas A: Comparison of methods for detection of Blastocystis infection in routinely submitted stool samples and also in IBS/IBD patients in Ankara, Turkey. PLOS ONE 2010, 5:e15484.

5. Zaman V, Khan KZ: A comparison of direct microscopy with culture for the diagnosis of Blastocystis hominis. Southeast Asian J Trop Med Public Health 1994, 25:792-793.

6. Leelayoova S, Taamasri P, Rangsin R, Naaglor T, Thathaisong U, Mungthin M: In-vitro cultivation: a sensitive method for detecting Blastocystis hominis. Ann Trop Med Parasitol 2002, 96:803-807.

7. Suresh K, Smith H: Comparison of methods for detecting Blastocystis hominis. Eur J Clin Microbiol Infect Dis 2004, 23:509-511.

8. Stark D, van Hal S, Marriott D, Elis J, Harkness J: Irritable bowel syndrome: a review on the role of intestinal protozoa and the importance of their detection and diagnosis. Int J Parasitol 2007, 37:11-20.

9. Boorom KF, Smith H, Nimri L, Viscogliosi E, Spanakos G, Parkar U, Li LH, Zhou XN, Ok UZ, Leelayoova S, Jones MS: Oh my aching gut: irritable bowel syndrome, Blastocystis and asymptomatic infection. Parasit Vectors 2008, 1:40.

10. Stensvold CR, Nielsen HV, Molbak K, Smith HV: Pursuing the clinical significance of Blastocystis-diagnostic limitations. Trends Parasitol 2009, 25:23-29.

11. Giacometti A, Cirioni O, Fiorentini A, Fortuna M, Scalise G: Irritable bowel syndrome in patients with Blastocystis hominis infection. Eur J Clin Microbiol Infect Dis 1999, 18:436-439.

12. Yakoob J, Jafri W, Jafri N, Khan R, Islam M, Beg MA, Zaman V: Irritable bowel syndrome: in search of an etiology: role of Blastocystis hominis. Am J Trop Med Hyg 2004, 70:383-385.

13. Dogruman-Al F, Kustimur S, Yoshikawa H, Tuncer C, Simsek Z, Tanyuksel M, Araz E, Boorom K: Blastocystis subtype in irritable bowel syndrome and inflammatory bowel disease in Ankara, Turkey. Mem Inst Oswaldo Cruz 2009, 104:724-727.

14. Jones MS, Whipps CM, Ganac RD, Hudson NR, Boroom K: Association of Blastocystis subtype 3 and 1 with patients from an Oregon community presenting with chronic gastrointestinal illness. Parasitol Res 2009, 104:341-345.

15. Salim HR, Kumar GS, Vellayan S, Mak JW, Anuar AK, Init I, Vennila GD, Saminathan R, Ramakrishnan K: Blastocystis in animal handlers. Parasitol Res 1999, 85:1032-1033.

16. Suresh K, Salim HR, Jamaiah I, Anuar AK: Blastocystis hominis in high-rise flat dwellers in Kuala Lumpur, Malaysia. Trans R Soc Trop Med Hyg 2001, 95:377-378

17. Abe N, Wu Z, Yoshikawa H: Molecular characterization of Blastocystis isolates from birds by PCR with diagnostic primers and restriction fragment length polymorphism analysis of the small subunit ribosomal RNA gene. Parasitol Res 2003, 89:393-396.

18. Leelayoova $S$, Siripattanapipong $S$, Thathaisong $U$, Naaglor T, Taamasri $P$, Piyaraj P, Mungthin M: Drinking water: a possible source of Blastocystis spp. subtype 1 infection in school children of a rural community in central Thailand. Am J Trop Med Hyg 2008, 79:401-406.

19. Noor Azian MY, San YM, Gan CC, Yusri MY, Nurulsyamzawaty Y, Zuhaizan $\mathrm{AH}$, Maslawaty MN, Norparina I, Vythilingam I: Prevalence of intestinal protozoa in an aborigine community in Pahang, Malaysia. Trop Biomed 2007, 24:55-62.

20. Ithoi I, Azman J, Mak JW, Wan Yusoff WS, Rohela M: Occurrence of Blastocystis in water of two rivers from recreational areas in Malaysia. J Parasitol Res 2011, doi:10.1155/2011/123916.

21. Abdulsalam AM, Ithoi I, Al-Mekhlafi HM, Ahmed E, Surin J, Mak JW: Drinking water is a significant predictor of Blastocystis infection among rural Malaysian primary schoolchildren. Parasitology 2012, 139:1014-1020.

22. Anuar TS, Al-Mekhlafi HM, Abdul Ghani MK, Osman E, Mohd Yasin A, Nordin A, Nor Azreen S, Md Salleh F, Ghazali N, Bernadus M, Moktar N: Giardiasis among different tribes of Orang Asli in Malaysia: Highlighting the 
presence of other family members infected with Giardia intestinalis as a main risk factor. Int J Parasitol 2012, 42:871-880

23. Kish L: Survey sampling. New York: John Wiley \& Sons, Inc; 1968. London.

24. Sinniah B, Rajeswari B: Blastocystis hominis infection, a cause of human diarrhea. Southeast Asian J Trop Med Public Health 1994, 25:490-493.

25. Rajah SH, Suresh KG, Vellayan S, Mak JW, Khairul Anuar A, Init I, Vennila GD, Saminathan R, Ramakrishnan K: Blastocystis in animal handlers. Parasitol Res 1999, 85:1032-1033.

26. Lwanga SK, Lemeshow S: Sample size determination in health studies: A practical manual. Geneva, Switzerland: World Health Organization; 1991.

27. Salleh FM, Anuar TS, Yasin AM, Moktar N: Wintergreen oil: A novel method in Wheatley's trichrome staining technique. J Microbiol Methods 2012 , 91:174-178.

28. Fleck SL, Moody AH: Diagnostic Technique in Medical Parasitology 11th ed. Cambridge: Cambridge U.P; 1993:10-14.

29. Leelayoova S, Rangsin R, Taamasri $P$, Naaglor $T$, Thathaisong U, Mungthin M: Evidence of waterborne transmission of Blastocystis hominis. Am J Trop Med Hyg 2004, 70:658-662.

30. Yan Y, Su S, Ye J, Lai X, Lai R, Liao H, Chen G, Zhang R, Hou Z, Luo X: Blastocystis sp. subtype 5: a possibly zoonotic genotype. Parasitol Res 2007, 101:1527-1532.

31. Yoshikawa H, Morimoto $K$, Wu Z, Singh M, Hashimoto T: Problems in speciation in the genus Blastocystis. Trends Parasitol 2004, 20:251-255.

32. Kuo HY, Chiang DH, Wang CC, Chen TL, Fung CP, Lin CP, Cho WL, Liu C: Clinical significance of Blastocystis hominis: experience from a medical center in northern Taiwan. J Microbiol Immunol Infect 2008, 41:222-226.

33. Lee LI, Chye T, Karmacharya BM, Govind SK: Blastocystis sp.: waterborn zoonotic organism, a possibility? Parasit Vectors 2012, 5:130.

34. Yaicharoen R, Ngrenngarmlert W, Wongjindanon N, Sripochang S, Kiatfuengfoo R: Infection of Blastocystis hominis in primary schoolchildren from Nakhon Pathom province, Thailand. Trop Biomed 2006, 23:117-122.

35. Menon BS, Abdullah M, Mahamud F, Singh B: Brief report: Intestinal parasites in Malaysian children with cancer. J Trop Pediatr 1999, 45:241-242.

36. Mohamed Kamel AG, Hartini Y: Blastocystis hominis: its presence in the faecal samples of Orang Asli children at Pos Lenjang, Pahang, Malaysia. Sains Malaysiana 2011, 40:1123-1127.

37. Nimri LF: Evidence of an epidemic of Blastocystis hominis infections in preschool-children in Northern Jordan. J Clin Microbiol 1993, 31:2706-2708.

38. Nascimento SA, Moitinho MD: Blastocystis hominis and other intestinal parasites in a communitu of Pitannga City Parana State, Brazil. Rev Inst Med Trop São Paulo 2005, 47:213-217.

39. Boeke CE, Mora-Plazas M, Forero Y, Villamor E: Intestinal protozoan infections in relation to nutritional status and gastrointestinal morbidity in Colombian schoolchildren. J Trop Pediatr 2010, 56:299-306.

40. Lee IL, Tan TC, Tan PC, Nanthiney DR, Biraj MK, Surendra KM, Suresh KG: Predominance of Blastocystis sp. subtype 4 in rural communities, Nepal. Parasitol Res 2012, 110:1553-1562.

41. Rayan P, Verghese S, McDonnell P: Geographical location and age affects the incidence of parasitic infestations in schoolchildren. Indian J Pathol Microbiol 2010, 53:498-504

42. El-Masry NA, Bassily S, Farid Z, Aziz AG: Potential clinical significance of Blastocystis hominis in Egypt. Trans R Soc Trop Med Hyg 1990, 84:695.

43. Baldo ET, Belizario W, De Leon WU, Kong HH, Chung DI: Infection status of intestinal parasites in children living in residential institutions in Metro Manila, the Philippines. Korean J Parasitol 2004, 42:67-70.

44. Gamboa MI, Navone GT, Orden AB, Torres MF, Castro LE, Oyhenart EE: Socio-environmental conditions, intestinal parasitic infections and nutritional status in children from a suburban neighborhood of La Plata, Argentina. Acta Trop 2011, 118:184-189.

45. Li LH, Zhang XP, Lv S, Zhang L, Yoshikawa H, Zhiliang W, Steinmann P, Utzinger J, Tong XM, Chen SH, Zhou XN: Cross-sectional surveys and subtype classification of human Blastocystis isolates from four epidemiological settings in China. Parasitol Res 2007, 102:83-90.

46. Al-Fellani MA, Khan AH, Al-Gazoui RM, Zaid MK, Al-Ferjani MA: Prevalence and clinical features of Blastocystis hominis infection among patients in Sebha, Libya. Sultan Qaboos Univ Med J 2007, 7:35-40.

47. Wang KX, Li CP, Wang J, Cui YB: Epidemiological survey of Blastocystis hominis in Huainan City, Anhui Province, China. World J Gastroenterol 2002, 8:928-932

48. Shahrul Anuar T, Al-Mekhlafi HM, Abdul Ghani MK, Osman E, Mohd Yasin A, Nordin A, Nor Azreen S, Md Salleh F, Ghazali N, Bernadus M, Moktar N:
Prevalence and risk factors associated with Entamoeba histolytica/dispar/ moshkovskii infection among three Orang Asli ethnic groups in Malaysia. PLoS One 2012, 7:e48165

49. Kain KC, Noble MA, Freeman HJ, Barteluk RL: Epidemiology and clinical features associated with Blastocystis hominis infection. Diagn Microbiol Infect Dis 1987, 8:235-244.

50. Zaki M, Zaman V, Sheikh NA: Resistance of Blastocystis hominis cysts to chlorine. J Pakistan Med Assoc 1996, 46:178-179.

51. Zaman V, Howe J, Ng M: Ultrastructure of Blastocystis hominis cysts. Parasitol Res 1995, 81:465-469.

52. Moe KT, Singh M, Howe J, Ho LC, Tan SW, Ng GC, Chen XQ, Yap EH: Observation on the ultrastructure and viability of the cystic stage of Blastocystis hominis from human feces. Parasitol Res 1996, 82:439-444.

53. Guglielmetti P, Cellesi C, Figura N, Rossolini A: Family outbreak of Blastocystis hominis associated gastroenteritis. Lancet 1989, 2:1394.

54. Pipatsatitpong D, Rangsin R, Leelayoova S, Naaglor T, Mungthin M: Incidence and risk factors of Blastocystis infection in an orphanage in Bangkok, Thailand. Parasit Vectors 2012, 5:37.

55. Sanad MM, Darwish RM, Yousef SM, Nassef NE: Blastocystis hominis: laboratory identification and clinical relevance. J Trop Med 1991, 1:61-70.

56. Torres P, Miranda JC, Flores L, Riquelme J, Franjola R, Perez J, Auad S, Hermosilla C, Riquelme S: Blastocystosis and other intestinal protozoan infections in human riverside communities from Valdivia River Basin, Chile. Rev Inst Med Trop São Paulo 1992, 34:557-564.

57. Yamada M, Matsumoto Y, Tegoshi T, Yoshida Y: The prevalence of Blastocystis hominis infection in humans in Kyoto City. Jpn J Trop Med Hyg 1987, 15:158-159.

58. Hunt ALC, Goldsmid JM, Pasha M: Enteric pathogens in mentally handicapped patients in hospital. Med J Aust 1990, 152:277-278.

59. Miller RA, Minshew BH: Blastocystis hominis: an organism in search of a disease. Rev Infect Dis 1988, 10:930-938.

60. Hussain Qadri SM, Al-Okaili GA, Al-Dayel F: Clinical significance of Blastocystis hominis. J Clin Microbiol 1989, 27:2407-2409.

61. Aldeen WE, Hale D: Use of Hemo-De to eliminate toxic agents used for concentration and trichrome staining of intestinal parasites. J Clin Microbiol 1992, 30:1893-1895.

62. Clark CG, Diamond LS: Methods for cultivation of luminal parasitic protists of clinical importance. Clin Microbiol Rev 2002, 15:329-341.

doi:10.1186/1756-3305-6-40

Cite this article as: Anuar et al:: Blastocystis infection in Malaysia: Evidence of waterborne and human-to-human transmissions among the Proto-Malay, Negrito and Senoi tribes of Orang Asli. Parasites \& Vectors 2013 6:40.

\section{Submit your next manuscript to BioMed Central and take full advantage of:}

- Convenient online submission

- Thorough peer review

- No space constraints or color figure charges

- Immediate publication on acceptance

- Inclusion in PubMed, CAS, Scopus and Google Scholar

- Research which is freely available for redistribution 